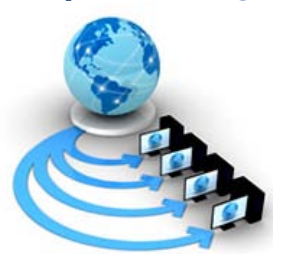

Volume 9, No. 3, May-June 2018

ISSN No. 0976-5697

International Journal of Advanced Research in Computer Science

RESEARCH PAPER

Available Online at www.ijarcs.info

\title{
IMPLEMENTING AN EMBEDDED BASED AUTOMATIC SCARP COLLECTOR BOT IN WATERBODIES
}

\author{
P.Hari Babu ${ }^{1}$, Naveena ${ }^{2}$, S.Sowmya ${ }^{3}$, Ch.Rambabu ${ }^{4}$, N.Prasanth ${ }^{5}$ \\ Department of Electronics and Communication Engineering, \\ MLR Institute of Technology, Hyderabad,India
}

\begin{abstract}
In introduce period, there is a loads of water contamination because of waste flotsam and jetsam in the water bodies. Due to increment in water contamination as waste trash; it is hampering the life of oceanic creature what's more, make their life in peril. Also now and then the sea-going creature has a tendency to eat squander trash thinking about it as nourishment; which at last reason the demise of creatures. Because of dirtied water, numerous skin ailments to mankind are watched. The smell discharged from contaminated water leads outcomes in air. So that to lessen water contamination we are endeavoring to make waterway cleanup machine. "Programmed scrap gatherer pontoon in water bodies" a machine which includes in expelling waste flotsam and jetsam from the water surface and securely arrange from the water bodies to the bank of the stream. In this model, we are utilizing dc engines and transport line setup to gather squander water flotsam and jetsam, plastics and trash. Arduino is utilized as a part of request to transmit the information to engine drivers. In this instrument, AVR Studio is utilized to play out the code. The client can control a pontoon by means of bluetooth. The task of bluetooth is done through remote controlled framework.
\end{abstract}

Keywords: arduino mega, convener belt, water bot, Bluetooth, cleanup machine.

\section{INTRODUCTION}

Transfer of plastic waste has developed as an imperative ecological challenge in this world where plastics make up as much as one-tenth of the strong waste stream. In well-to-do GCC countries, plastic waste piece in city strong waste is around $12-16$ percent. Plastic waste in the locale is persistently expanding because of expanding utilization of plastics in everyday life. Plastic waste is a wellspring of ozone harming substance discharges and environmental harm. Dominant part of the things found on shorelines over the locale contains plastic which represent a genuine risk to marine life. Plastic waste transfer is a noteworthy test due to non-biodegradable nature of plastics and such squanders are unmistakably present in landfill locales for quite a while. Marine flotsam and jetsam, otherwise called marine litter, is human - made waste that has intentionally or unintentionally been discharged in a lake, ocean, sea or conduit. Skimming maritime flotsam and jetsam has a tendency to gather at the focal point of gyres and on coastlines, every now and again washing around, when it is known as shoreline litter or tide wrack[5]. Think transfer of squanders adrift is called sea dumping. Normally happening flotsam and jetsam, for example, driftwood, are additionally present. With the expanding utilization of plastic, human impact has turned into an issue the same number of sorts of plastics don't biodegrade. Waterborne plastic represents a genuine risk to angle, seabirds, marine reptiles, and marine warm blooded creatures, and also to vessels and coasts.

\section{PROBLEM DEFINITION}

Environmental impact: Numerous creatures that live on or in the ocean expend debris By botch, as it regularly appears to be like their common prey. Bulky plastic flotsam and jetsam may turn out to be for all Time held up in the stomach related tracts of these creatures, bolting the section of sustenance and causing destruction through starvation or sullying. Small skimming plastic particles also take after zooplankton, which can lead channel feeders to eat up them and influence them to enter the ocean common lifestyle. In tests taken from the North Pacific Gyre in 1999 by the Algalita Marine Research Foundation, the mass of plastic outperformed that of zooplankton by a factor of six. Hazardous included substances used as a piece of plastic gathering can deplete into their surroundings when introduced to water[6]. Waterborne hydrophobic poisons accumulate and enhance on the surface of plastic junk, in this way making plastic more deadly in the ocean than it would be shoreward's. Hydrophobic contaminants bio - total in oily tissues, biomagnifying up the advanced lifestyle and convincing zenith predators and individuals. Some plastic included substances aggravate the endocrine system when consumed; others can smother the sheltered structure or decrease regenerative rates[3].

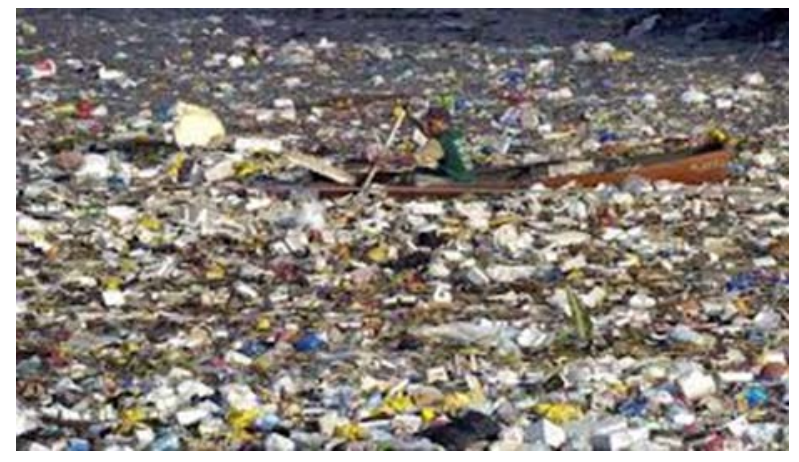

Figure.1. Plastic waste over the ganga

Debris removal: Methods for gathering and evacuating marine (or riverine) trash incorporate the utilization of garbage skimmer vessels. Gadgets, for example, these can be utilized where drifting flotsam and jetsam displays a risk to route. When flotsam and jetsam moves toward becoming 
"shoreline litter", accumulation by hand and concentrated shoreline cleaning machines are utilized to assemble the trash. Utilization of skimmer water crafts is expensive method for plastic expulsion and it require steady upkeep and furthermore specialists for doing the procedure. In lakes or close to the drift, manual expulsion is polished today in a few zones, which isn't compelling since the plastic must be evacuated ceaselessly else the plastic may achieve the ocean .On the ocean, the evacuation of manufactured trash is still in its early stages. However a few undertakings have been begun which utilized boats with nets (Kaisei and New Horizon) to get a few plastics, essentially for inquire about purposes[4]. It is worked from aluminum and intended for simplicity of task and minimal effort of proprietorship. The channel framework can be changed in accordance with gather distinctive sizes of junk. Marina Cleaners are accessible in crisp water or salt water forms and highlight an articulating vertical wing catch framework that conveys flotsam and jetsam to the front get transport.

\section{METHODOLOGY}

The subjects of the investigation were waterways and water bodies in our territory which were influenced by the issue of plastic waste flotsam and jetsam. In our investigation we gathered example of plastics from the branches of knowledge and did profound examination on sort of plastic that been found. In the examination we discovered waste examples contains plastics like[1],

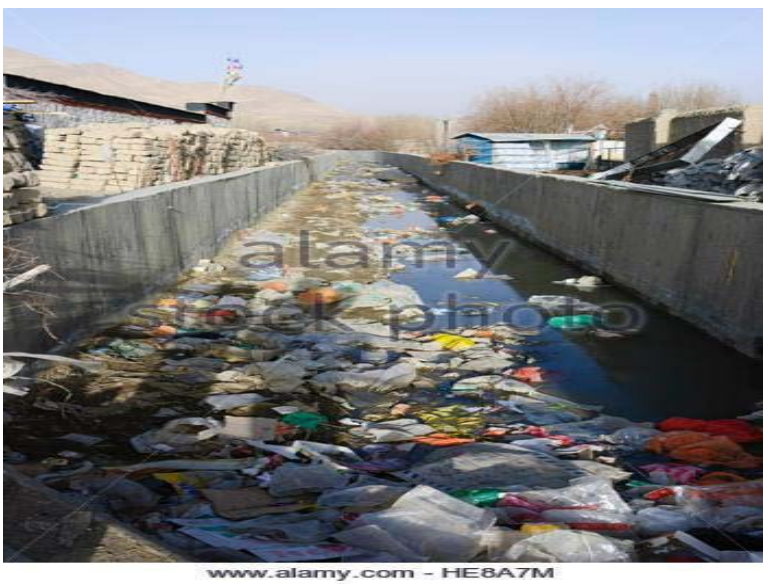

Figure.2. Continuous accumulation of waste in the flowing river bodies

-Plastic packs which we use in everyday life having microns going from 40microns or more.

-PET jugs of various drinks, oils and so on.

-Plastic nets made of polyamides like nylons.

-Children's toys parts.

-Plastic containers and holders utilized as a part of regular family life.

-Other minute estimated plastic squanders

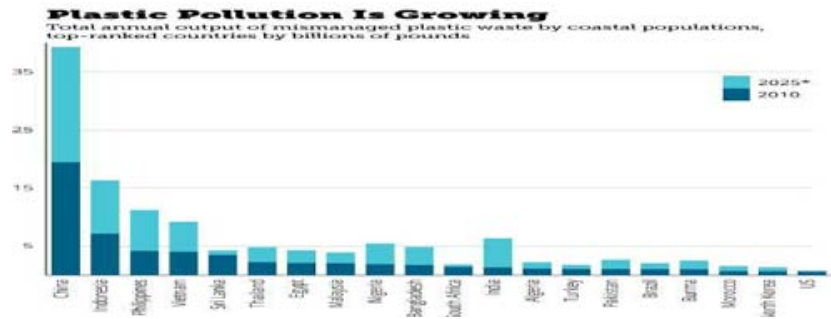

Figure.2. Graph showing the plastic debris around the world

\section{COMPONENTS AND DES CRIPTION}

The major parts employed for making of the automatic scrap collector boat in waterbodies are DCmotor (10rpm,300rpm), Conveyor Belt , L293D motor driver,12Vbattery,voltage regulator(5v,12v), Arduino mega, Bluetooth module, wheels

DC Motor : 300RPM Centre Shaft Economy Series DC Motor is high quality low cost DC geared motor. It has steel gears and pinions to ensure longer life and better wear and tear properties. The gears are fixed on hardened steel spindles polished to a mirror finish. The output shaft rotates in a plastic bushing. The whole assembly is covered with a plastic ring. Gearbox is sealed and lubricated with lithium grease and require no maintenance. The motor is screwed to the gear box from inside. Although motor gives 300 RPM at $12 \mathrm{~V}$ but motor runs smoothly from $4 \mathrm{~V}$ to $12 \mathrm{~V}$ and gives wide range of RPM, and torque. It is used for the movement of boat by connecting wheels to it.

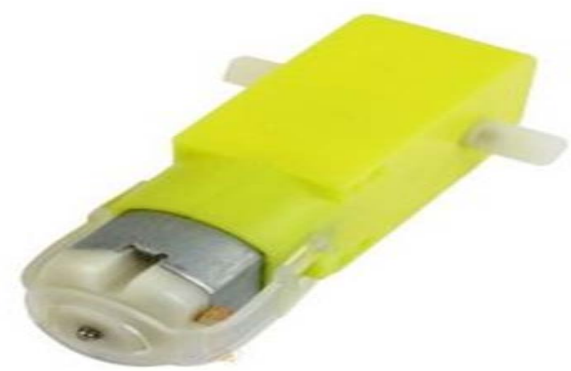

Figure.4. 300RPM DC motor

10RPM: This DC Motor with Metal Gear Head is perfect for low RPM i.e. fig1.6. High Torque application like lifting a question through Hook and furthermore valuable for different apply autonomy applications. This Motor has following electrical and mechanical details

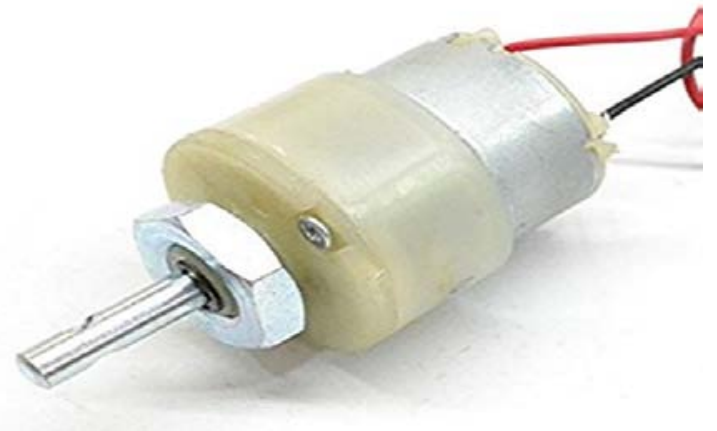

Figure.5. 10RPM DC motor

Voltage regulator- 
A LM7805 Voltage Regulator is a voltage controller that yields +5 volts. A simple method to recollect the voltage yield by a LM78XX arrangement of voltage controllers is the last two digits of the number. A LM7805 closes with "05"; hence, it yields 5 volts. The "78" section is only the tradition that the chip producers use to signify the arrangement of controllers that yield positive voltage

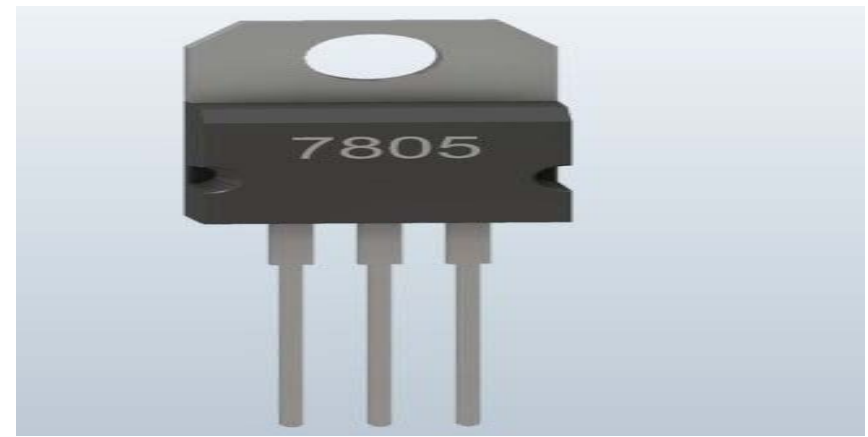

Figure.6.7805 voltage regulator

L293D: -L293D is a run of the mill Motor driver or Motor Driver IC which permits DC engine to drive on either bearing. L293D is a 16-stick IC which can control an arrangement of two DC engines all the while toward any path. It implies that you can control two DC engine with a solitary L293D IC. Double H-connect Motor Driver incorporated circuit (IC).

Arduino mega-The Arduino Mega can be fueled by means of the USB association or with an outside power supply. The power source is chosen naturally. Outer (non-USB) power can come either from an AC-to-DC connector (divider wart) or battery.

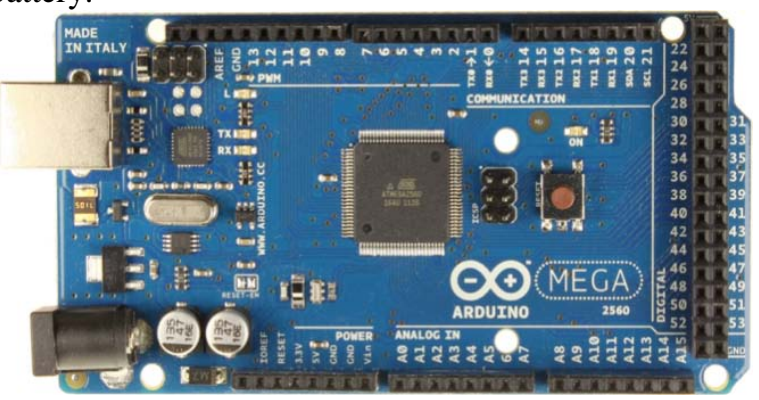

Figure.8.Arduino mega

\section{WORKING}

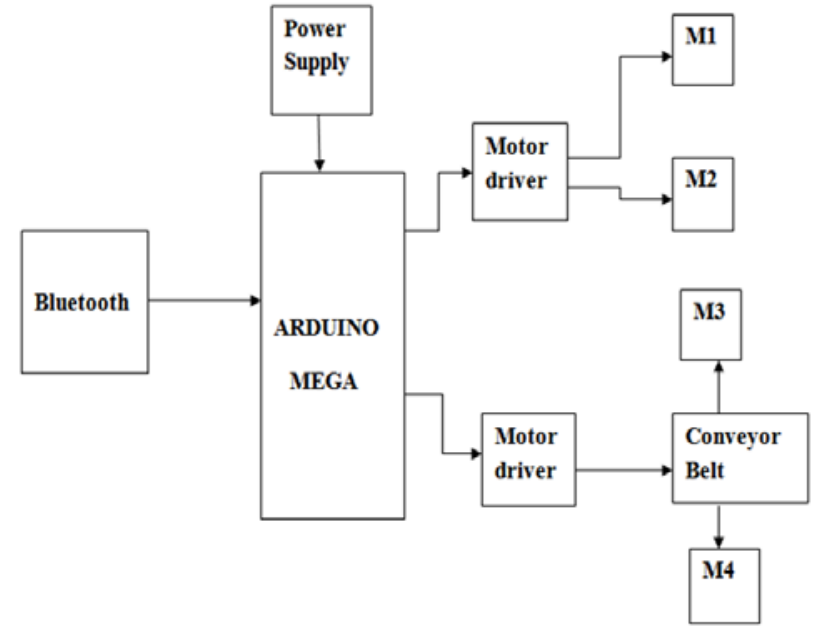

Figure.9. Block Diagram

In this venture the principle point of this machine is to lift the waste flotsam and jetsam from the water surface and arrange them in the plate. It comprise game plan of the transport which is set on the pole. At the point when these waterwheels gets turned; the power is transmitted to transport framework by methods for belt drives. As the transport is moved, it gathers the water flotsam and jetsam, squander trash \&plastics from water bodies[2]. As the machine is set in the water the waste flotsam and jetsam will get lifted and it moves upward way

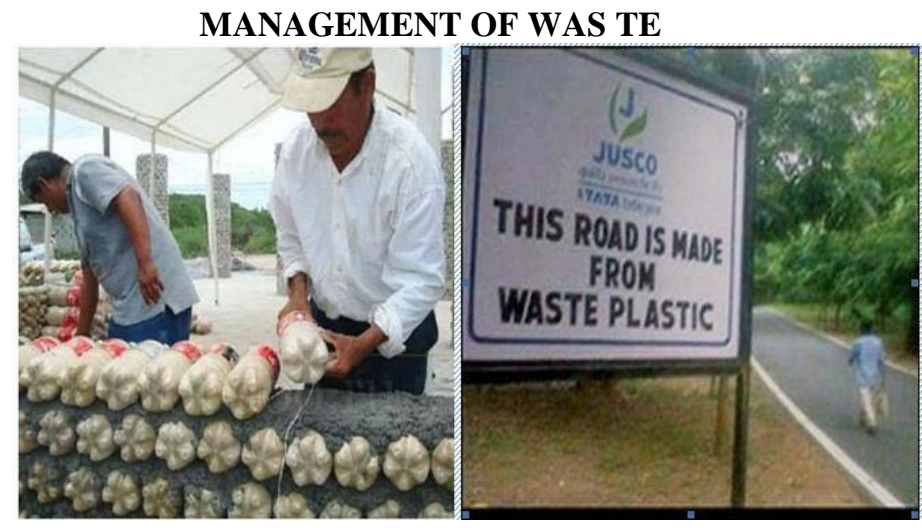

Figure.10. Uses of plastics in the future

\section{FUTURE S COPE}

By modifying to remote controlled plastic remover-This undertaking can be changed by utilizing a wirelesss controlled gliding base so that the controller from the shore can without much of a stretch clean the water bodies simply through remote framework. The transport framework is connected to a gliding base as in a dredger settled with engines to running the base. This framework to be controlled by a beneficiary unit settled in the gliding unit. 


\section{CONCLUS ION\& RESULTS}

The favorable position which accomplished from our Idea is of a better valuable one and we are glad in having eco cordial Idea. Normal ones make it difficult to acquire and feels cumbersome work, our thought give the response to this issue through this undertaking we can be ready to comprehend the troublesome lies in keeping up the resistances and furthermore the quality. Also we found some issues that can be occur such as the stream of water is a vital factor in successful evacuation of junk. There ought to be sufficient surface stream speed to hold the wastes against the turning net. The control produced from sunlight based board might vacillate due to cloud influence the charging process. Since the framework is placed in water, the precaution measurement taken is to give, for example, painting, covering, and coupling to a giving up anode, oil and different procedures to oppose the structure from consumption. The issues that we confronted will be cleared what's more, encourage change will be improved in future to achieve specialized and proficient one. This Idea makes a motivational concern toward the Government and social to work with condition wellbeing, and to make mindful of the earnestness of these issues in Future

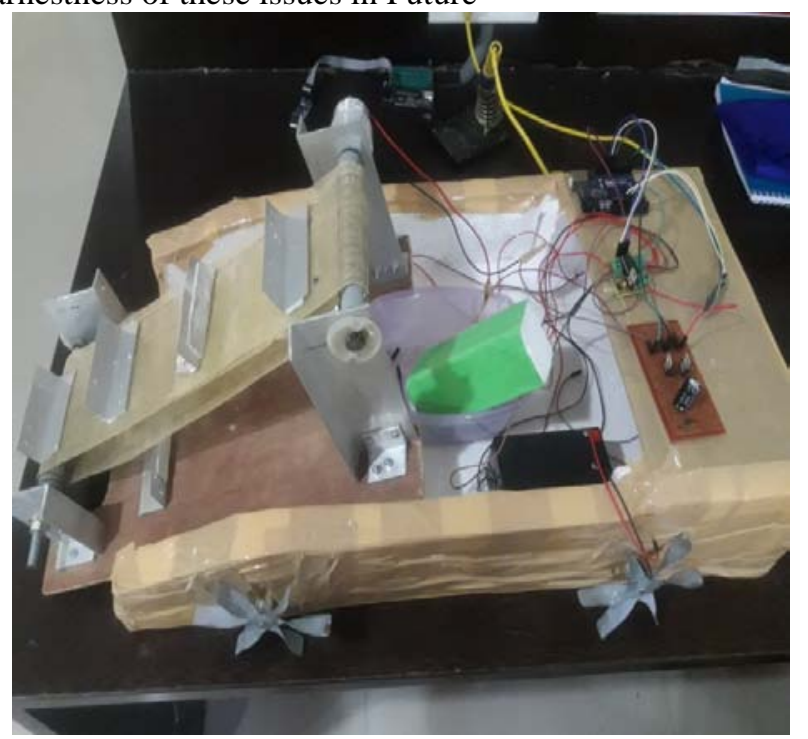

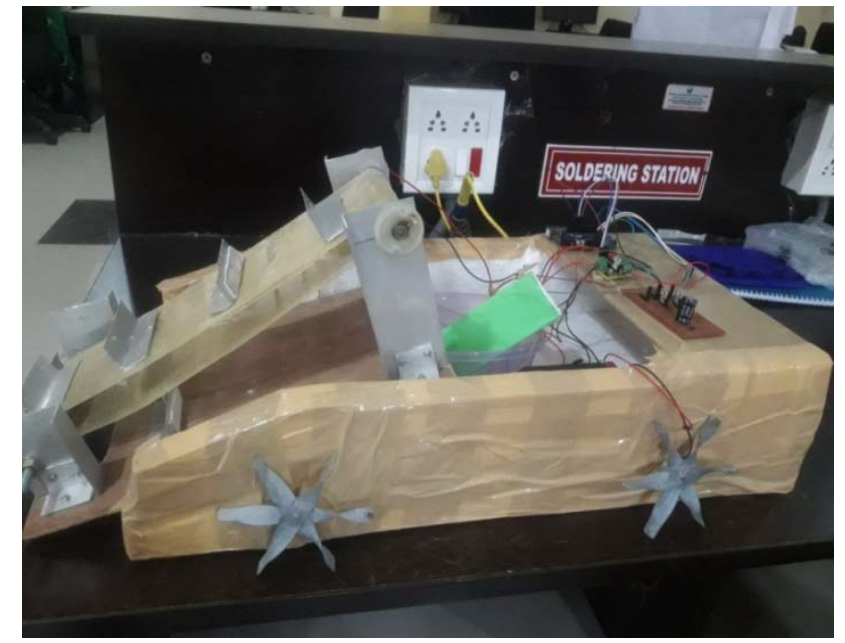

Figure.11. Prototype model of scarp collecting bot in waterbodies

\section{REFERENCE}

[1] BasantRai,pollution and conservation of Ganga river in modern India , International journal of scientific and research publication Volume-3,April 2013,ISSN22503153,PP 1-4.

[2] Khurmi R. S., Gupta J.K., A textbook of machine design, first edition, S. ChanPublication,1979.

[3] Priyam Das ,Kenneth R. Tamminga,Thegangas and the GAP,AnAssesment of effect to clean a sacred river,sustainability 2012,1647-1668,pp. 1647-1668.

[4] RajendraPatil,RahulItnar,SagarAhirrao,AmolJadhav\&amp; Ajay Dhumal, Study of river harvesting \&amp; trash cleaning machine, International journal of innovative research in science \&amp; Engineering,Vol.No.2,March 2016,pp.422-431.

[5] Wang Jianlong, Point sources of pollution: local effect and its control, Volume II technology for water pollution control, Tsinghua university, Bijing,China, Encyclopedia of life support system(EOLSS0,pp.1-10.

Wolfgang Radhuber, Trashrack cleaning the past-the present-the future ,15 th International Seminar on hydropower plant- Hydropower plant in context the climate change,Vienna,2008,pp.1-16. 